\title{
The Relationship between Neuroticism, Emotion Regulation, and Academic Stress with Depression Symptoms in Indonesian Medical Student
}

\author{
Janice Valencia*(D), Frikson Christian (D) \\ Faculty of Psychology, University of Surabaya, East Java, Indonesia
}

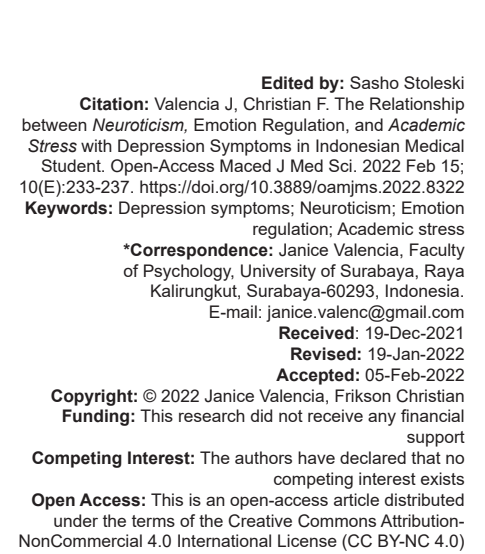

Introduction

Depression is predicted to take the first rank to contribute to the global burden of disease by 2030 [1], [2]. Based on Global Burden of Disease (2017), the number of individuals with depression is 264 million globally. Meanwhile, $53 \%$ of students in the United States experience depression since entering the university. This figure is not much different from France, Kenya, and Malaysia [3], [4]. The prevalence rate of women is much higher than that of men; there are one in six people affected by depression, and the rate in women is 2 times higher than that of men [5], [6].

The prevalence of individuals who experience depression symptoms in the United States increased in 2019, gained individuals who experienced mild-tosevere depressive symptoms by about $52.5 \%$ [7]. In Indonesia, the prevalence has reached $3.7 \%$ or about 9 million people who experience depression [3], [8], [9]. Based on the Ministry of Health of the Republic of Indonesia, 14 million people aged 15 years old and above experienced mental disorders in 2013 , including anxiety and depression [9], [10]. Particularly among medical students, the causes of depression symptoms include student interest in the field studied, age; in which students with older ages are more susceptible to the emergence of depressive symptoms due to more stressors, such as the economy, graduation targets, work, and married life [11]. Meanwhile, the socioeconomic factors include the students with low family economic conditions are more at risk of experiencing depression symptoms [11].

There are several factors causing individuals to experience depression symptoms based on the Conservation of Resources (COR) theory proposed by Hobfoll and Golembiewski (1998, 2000). In this case, each individual has internal and external resources. Internal resources are resources that the individual owns. When an individual loses resources, the individual may experience acute losses [12]. Individuals who do not adapt at the time of resource loss will experience a second loss, leading to chronic losses [13]. Personality in COR theory plays a role in helping individuals adopt when they lose resources. Therefore, individuals will not experience secondary losses and chronic losses. This can strengthen the depression symptoms emerged [14].

Eysenck's personality theory (1967) explained three dimensions of personality: Extraversion, Neuroticism, and psychoticism. Neuroticism in individuals has strong heredity. Research that has been conducted previously 


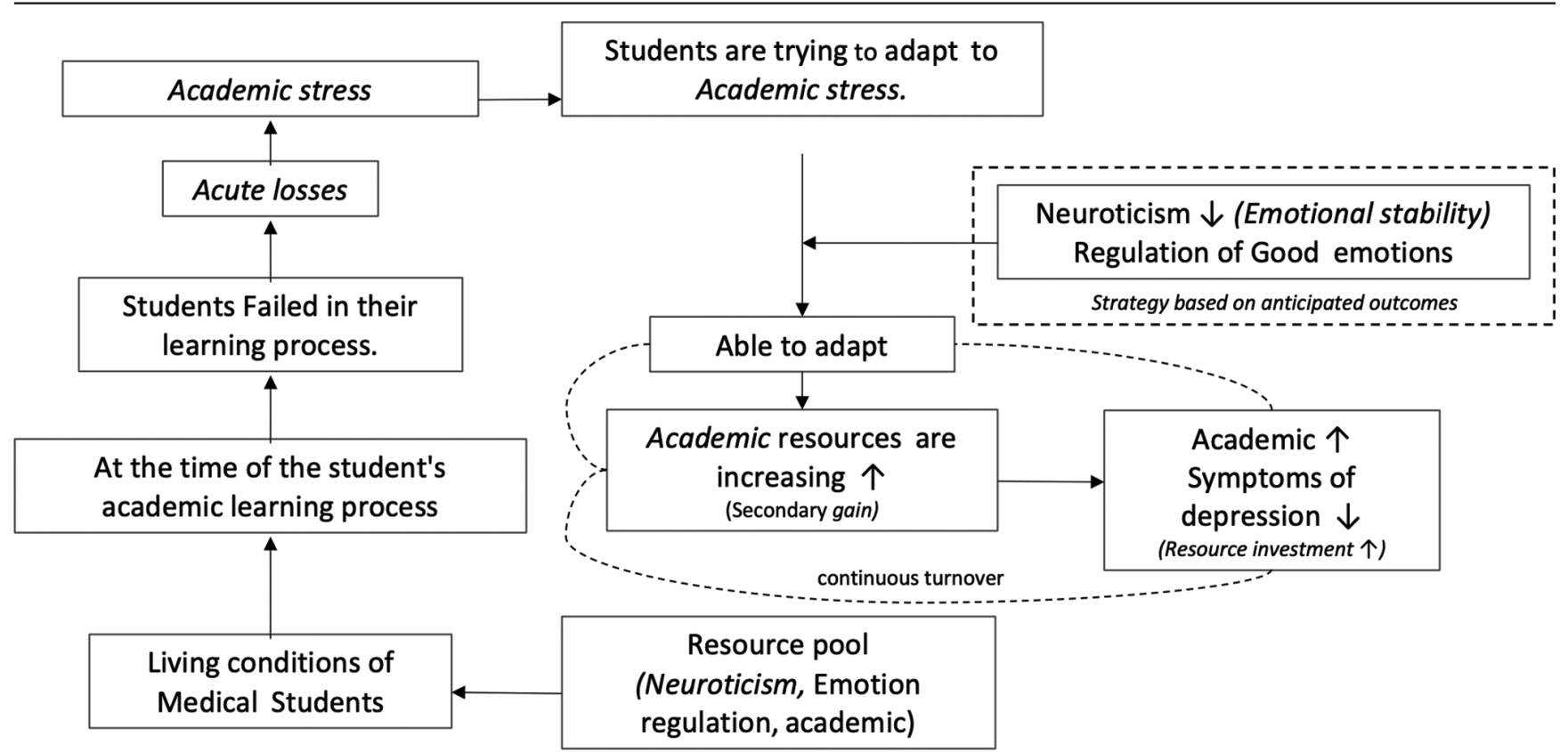

Figure 1: Theory schema conservation of resource based on the secondary gain in medical student

found that people who have high scores in Neuroticism tend to overreact emotionally and have difficulty returning to normal after being emotionally stimulated. Eysenck accepts the diathesis-stress model, which means that some individuals are more susceptible to disease because of genetic factor or learned weaknesses make them vulnerable. Inventory developed by Eysenck measures extraversion and neuroticism independently with almost zero correlation [15].

This supports the finding that individuals with neuroticism have a low tolerance to stress and is also aversive to stimuli. Individuals with high neuroticism often interpret ordinary situations as threatening and minor frustrating conditions as hopeless difficulties [16], [17].

Improper regulation of emotions can be one of the factors individuals experience depression symptoms. Individuals who experience depression symptoms are known to have improper emotional regulation, especially during adverse situations; in which the individual has difficulty regulating negative emotions. Experiencing negative emotions for a long time can emerge the possibility of the individual experiencing depression symptoms [18]. Individuals who have difficulty regulating emotions can be in the form of rumination. Individuals with high neuroticism are more likely to regulate their emotions with rumination [19]. Rumination is the thought of individuals who constantly think about the causes and outcomes of adverse events and feelings arising from the negative event regardless of the problemsolving of the event [19], [20]. Neuroticism attends to instability in emotions and adapts individuals who are more neurotic, have excessive happiness, and indulge in negative affect [21]. Neuroticism influences the way individuals think, so individuals with high Neuroticism often focus on negative things and continuously feel and think about them. It can be a habit of the individual to regulate his emotions with rumination [19].

This inappropriate emotional regulation method cannot only cause depression symptoms but also increase recurrence in individuals with improper emotional regulation and depression symptoms compared to individuals who experience depression symptoms but have proper emotional regulation [18]. Individuals with high neuroticism are more sensitive and emotional to stimuli so that the individual more easily falls into hostile conditions. Individuals with it become quickly and have a more regular frequency to think about the adverse condition than the individual's low neuroticism; the cycle will become the individual's habit to use rumination. Being focus can cause individuals to think about their adverse condition and it will continuously worsen the negative effect so that it is more likely emerge the depression symptoms [19].

\section{Methods}

The population in this study was medical students in Malang. The characteristics of the intended population are the $4^{\text {th }}$ year medical students who will complete the academic stage and enter the professional stage. The hypothesis test in this study serves to test the relationships between independent and dependent variables. The hypothesis test employed multiple regression or double regression calculations. Multiple regression tests were also used to analyze the level of the relationship between independent variables and dependent variables.

The samples involved are 138 participants consisting of 71 women and 67 men. The average 
age of the participants was 20-24 years old. A total of 134 participants have an average family income in the upper-middle category. All participants were in the $4^{\text {th }}$ year of medical school.

\section{(CES-D)}

\section{The center for epidemiology-depression}

This instrument consists of four answer options, namely, 0 (no symptoms/never) and 3 (there are severe symptoms/almost always/always). The greater the number given, the more depression symptoms emerge. CES-D was developed by the National Institute of Mental Health Center for Epidemiology Scale; the CES-D scale can be used in clinical and non-clinical communities. In this study, the Indonesian version of CES-D was used.

There are 20 items on the CES-D scale: Depressive affect, positive affect, somatic disorder complaints, and interpersonal relationship disorders. On the CES-D scale, seven items represent depressive affect, four items represent positive affect, seven items represent somatic disorder complaints, and two points represent interpersonal relationship disorders.

\section{Big five inventory (BFI)-II}

Neuroticism measurements use the BFI scale that measures extraversion, agreeableness, conscientiousness, neuroticism, and openness. There are eight questions for extraversion, nine questions for agreement, nine questions for conscientiousness, eight questions for neuroticism, and 10 questions for openness. This instrument consists of 44 questions and five answer choices, namely, 0 (strongly disagree) and 5 (strongly agree). This study used the BFI neuroticism with negative emotionality aspects. The Indonesian version of the BFI neuroticism was used in this study [22]. This refers to the research that individuals with neuroticism can cause the individuals to experience depression [23]. The Big Five is allowed to take aspects of neuroticism alone [24]. This is because individuals with neuroticism have a high, negative effect that individuals with neuroticism be susceptible to depression. Based on Eysenck and Eysenck, 164 explain that neuroticism can be measured independently, with almost zero correlation.

\section{(DERS)}

\section{Difficulties in emotional regulation scale}

Measurement of emotion regulation was done using the DERS with five answer options, namely, 1 (never) and 5 (always). There are 36 questions on the DERS scale, namely, six items representing a response to unacceptable emotions, five points representing difficulty behaving bound to a specific purpose, six points representing difficulty controlling impulses, six points representing difficulty in realizing emotions, eight points representing the limitations of strategies to regulate emotions, and five points representing the difficulty in explaining emotions. The Indonesian version of the DERS was used in this study.

\section{Perception of academic stress (PAS)}

The measurement of academic stress using the PAS scale contained 18 questions. The Indonesian version of PAS was used in this study. There are three subscales on PAS, namely, the academic expectation scale (four items), the workload and examination scale (eight items), and the self-perception scale for academic students (six items). The PAS scale was measured using a questioner with a Likert model; there are 5 Likert points, 1 is very irrelevant, and 5 is very relevant.

In this case, the hypothesis test used multiple regression or double regression calculations. Multiple regression tests were also used to analyze the level of the relationship between the independent variables and dependent variables.

\section{Results}

Reliability test was conducted using alpha Cronbach with results obtained depression measuring instrument (CES-D) obtained CITC at the range of $0.198-0.834$ without any items aborted (Table 1). The number of CITC values that are not aborted due to consideration of the value of alpha Cronbach is 0.948 with a fair value $(>0.7)$. In the BFI neuroticism, there is a range of CITC of $0.382-0.759$, and no item was dropped with an alpha Cronbach value of 0.907 so that the BFI-N gauge can be declared reliable with a fair value $(>0.7)$. The emotional regulation measuring instrument (DERS) was obtained from the CITC at the range of $0.482-0.770$ with six items dropped. A total of six items were dropped because these items are lower than the reliability score of DERS. Item number 1 has CITC of 0.191 , number 7 has CITC of 0.65 , number 11 has CITC of 0.042 , number 20 has CITC of -0.036 , number 22 has CITC of -0.044 , and number 24 has CITC of -0.165 . The alpha Cronbach before the elimination of item was 0.931 , while after eliminating the six items, it became 0.955. The academic stress

Table 1: Reliability test CES-D, BFI-N, DERS, and PAS

\begin{tabular}{|c|c|c|c|c|c|}
\hline No & Variable & $\begin{array}{l}\text { Corrected item } \\
\text { total correlation }\end{array}$ & $\begin{array}{l}\text { Eliminated } \\
\text { items }\end{array}$ & $\begin{array}{l}\text { Used } \\
\text { items }\end{array}$ & $\begin{array}{l}\text { Alpha } \\
\text { Cronbach }\end{array}$ \\
\hline 1. & Depression & $0.198-0.834$ & - & 20 & 0.948 \\
\hline 2. & $\begin{array}{l}\text { Big Five Inventory } \\
\text { (Neuroticism) }\end{array}$ & $0.382-0.759$ & - & 12 & 0.907 \\
\hline 3. & $\begin{array}{l}\text { Regulation of } \\
\text { emotions }\end{array}$ & $0.482-0.770$ & 6 & 30 & 0.955 \\
\hline 4. & Academic stress & $0.306-0.734$ & - & 18 & 0.884 \\
\hline
\end{tabular}


measuring instrument PAS obtained CITC value at the range of $0.306-0.734$ without any items eliminated with satisfying reliability and alpha Cronbach value of 0.884 .

Table 2 describes a link between neuroticism, emotional regulation, academic stress, and depression symptoms in medical students. Based on the above analysis results, we obtained coefficients correlation $(R)$ of 0.808 , values $F$ of 83,800 , and $p=0.000$. Thus, since $\mathrm{p}<0.05$, the $\mathrm{Ho}$ is rejected and $\mathrm{H} 1$ is accepted with a significant value. Based on this, it can be concluded that there is a relationship between neuroticism, emotional regulation, and academic stress with depression symptoms. The value of $\mathrm{R}^{2}=0.652$ indicates that depression symptoms are simultaneously influenced by neuroticism, emotional regulation, and academic stress by $65.2 \%$. Meanwhile, the remaining $34.8 \%$ of depression symptoms are affected by other variables that were not disclosed in this study.

Table 2: Hypothesis test

\begin{tabular}{llllll}
\hline Hypothesis & IV-DV correlation & r & R square & F & Sig \\
\hline The relationship between & Depression & 0.808 & 0.652 & 83.800 & 0.000 \\
Neuroticism, emotional & symptoms, & & & & \\
regulation, and academic & Neuroticism, & & & & \\
stress with depression & Emotion & & & & \\
symptoms in medical students & $\begin{array}{l}\text { Regulation, } \\
\text { Academic Stress }\end{array}$ & & & & \\
& & &
\end{tabular}

\section{Discussion}

The results obtained support COR theory that neuroticism and emotion regulation can be an individual's internal resources. Neuroticism is based on Eysenck's theory (1967) that individuals with high neuroticism have stress relatedness compared to individuals with low neuroticism. In contrast, the external resources owned by medical school students are the process of academic life. Based on the COR scheme, broader life condition is a student's living conditions either broadly or specifically in their academic life. In the context of students, the academic process becomes an external resource because learning achievement is assessed from its academic success. When students fail to undergo the academic process, students will experience acute losses. This means that students lose these resources, with the academic burden that exists in the $4^{\text {th }}$ year of medical school who must complete the grades during the academic stage with a minimum of $\mathrm{C}$ score, final assignments, and the clinical chivalry examination that is included in the academic stress aspect, namely, stress related to academic assignments and examinations. By the COR scheme, students experience acute losses (Figure 1). Students who have difficulty regulating emotions and also have high Neuroticism have difficulty in adapting because they are more sensitive to the stress experienced so that negative emotions often appear. In addition, it also has an impact on the regulation of student emotions, difficulty in making decisions, thinking clearly, and doing effective coping. Therefore, neuroticism and difficulty in emotional regulation can influence the unsuccessful adaptation experienced while undergoing academic life. The condition of difficulty regulating emotions and high neuroticism will bring secondary losses, which has the impact of chronic losses (symptoms of strengthened depression). This turnaround explains principle 1 (Primacy of losses) proposed by Hobfoll (2018), where the obtained resources are less than the lost ones.

\section{Conclusion}

Based on the results of research consisting of hypothesis tests, data analysis, and discussions above, it can be concluded that:

1. High neuroticism, difficulty in regulating emotions, and academic stress have an essential role in developing depression symptoms in medical students. High neuroticism does not solely cause students to experience depression symptoms. However, difficulty in regulating emotions and experience in academic stress can cause students to experience depression symptoms.

2. Students who experience academic stress and have fewer resources (high neuroticism and difficulty in regulating emotions) will tend to experience unsuccessful adaptation so that it causes symptoms of more substantial depression (secondary losses). This can lead to chronic losses.

\section{References}

1. Sofija E, Harris N, Sebar B, Phung D. Who are the flourishing emerging adults on the Urban East coast of Australia? Int J Environ Res Public Health. 2021;18(3):1125. https://doi. org/10.3390/ijerph18031125

PMid:33514003

2. Mahmoud JS, Staten R, Hall LA, Lennie TA. The relationship among young adult college students' depression, anxiety, stress, demographics, life satisfaction, and coping styles. Issues Ment Health Nurs. 2012;33(3):149-56. https://doi.org/10.3109/0 1612840.2011.632708

PMid:22364426

3. Othieno CJ, Okoth RO, Peltzer K, Pengpid S, Malla LO Depression among university students in Kenya: Prevalence and sociodemographic correlates. J Affect Disord. 2014;165:120-5. https://doi.org/10.1016/j.jad.2014.04.070

PMid:24882188

4. Barker ET, Howard AL, Villemaire-Krajden R, Galambos NL. The rise and fall of depressive symptoms and academic 
stress in two samples of university students. $\mathrm{J}$ Youth Adolesc. 2018;47(6):1252-66. https://doi.org/10.1007/s10964-018-0822-9 PMid:29470761

5. Penninx BW, Milaneschi $\mathrm{Y}$, Lamers $\mathrm{F}$, Vogelzangs $\mathrm{N}$. Understanding the somatic consequences of depression: Biological mechanisms and the role of a depression symptom profile. BMC Med. 2013;11(1):129. https://doi. org/10.1186/1741-7015-11-129

PMid:23672628

6. Alonso J, Angermeyer MC, Bernert S, Bruffaerts R, Brugha TS, Bryson $\mathrm{H}$, et al. Prevalence of mental disorders in Europe: Results from the European study of the epidemiology of mental disorders (ESEMeD) project. Acta Psychiatr Scand. 2004;109(s420):21-7. https://doi.org/10.1111/j.1600-0047.2004.00327.x

PMid: 15128384

7. Ettman CK, Abdalla SM, Cohen GH, Sampson L, Vivier PM, Galea S. Prevalence of depression symptoms in US adults before and during the COVID-19 pandemic. JAMA Netw Open. 2020;3(9):e2019686. https://doi.org/10.1001/jamanetworkopen.2020.19686 PMid:32876685

8. Peltzer K, Pengpid S. High prevalence of depressive symptoms in a national sample of adults in Indonesia: Childhood adversity, sociodemographic factors and health risk behaviour. Asian J Psychiatry. 2018;33:52-9. https://doi.org/10.1016/j. ajp.2018.03.017

PMid:29529418

9. Fahmi M, Panjaitan NA, Habibie I, Siregar AY, Amarullah G, Rahma, et al. Does your neighborhood protect you from being depressed? A study on social trust and depression in Indonesia. BMC Public Health. 2019;19(1):1371.

10. Tsypes A, Angus DJ, Martin S, Kemkes K, Harmon-Jones E. Trait anger and the reward positivity. Personal Individ Differ. 2019;144:24-30.

11. Chen L, Wang L, Qiu XH, Yang XX, Qiao ZX, Yang YJ, et al. Depression among Chinese university students: Prevalence and socio-demographic correlates. PLoS One. 2013;8(3):e58379.

12. Hobfoll S, Golembiewski RT. Conservation of resources theory. In: Handbook of Organizational Behavior. United Kingdom: Routledge; 2000.

13. Hobfoll SE, Halbesleben J, Neveu JP, Westman M. Conservation of resources in the organizational context: The reality of resources and their consequences. Annu Rev Organ Psychol Organ Behav. 2018;5(1):103-28.

14. Hobfoll SE. The influence of culture, community, and the nestedself in the stress process: Advancing conservation of resources theory. Appl Psychol. 2001;50(3):337-421.

15. Eysenck SB, Eysenck HJ. An improved short questionnaire for the measurement of extraversion and neuroticism. Life Sci. 1964;3(10):1103-9. https://doi.org/10.1016/0024-3205(64)90125-0 PMid:14225366

16. Bhagat $\mathrm{V}$, Nayak RD. Neuroticism and academic performance of medical students. Int J Humanit Soc Sci Invent. 2014;3(1):51-5.

17. Matthews G, Deary IJ, Whiteman MC. Personality Traits. $3^{\text {rd }}$ ed. Cambridge: Cambridge University Press; 2009. p. 568.

18. Joormann J, Vanderlind WM. Emotion regulation in depression: The role of biased cognition and reduced cognitive control. Clin Psychol Sci. 2014;2(4):402-21.

19. Chen $\mathrm{X}, \mathrm{Pu}$ J, Shi $\mathrm{W}$, Zhou $\mathrm{Y}$. The impact of neuroticism on symptoms of anxiety and depression in elderly adults: The mediating role of rumination. Curr Psychol. 2020;39(1):42-50.

20. Nolen-Hoeksema S, Aldao A. Gender and age differences in emotion regulation strategies and their relationship to depressive symptoms. Personal Individ Differ. 2011;51(6):704-8.

21. Ormel J, Jeronimus BF, Kotov R, Riese H, Bos EH, Hankin B et al. Neuroticism and common mental disorders: Meaning and utility of a complex relationship. Clin Psychol Rev. 2013;33(5):686-97. https://doi.org/10.1016/j.cpr.2013.04.003 PMid:23702592

22. Ahya A, Siaputra IB. Validasi big five inventory-2 (BFI-2) untuk Indonesia: Belum sempurna tetapi valid dan reliabel mengukur kepribadian. J Psikol Ulayat. 2021;1-12.

23. Paulus DJ, Vanwoerden S, Norton PJ, Sharp C. Emotion dysregulation, psychological inflexibility, and shame as explanatory factors between neuroticism and depression. J Affect Disord. 2016;190:376-85. https://doi.org/10.1016/j. jad.2015.10.014 PMid:26546773

24. Griffith JW, Zinbarg RE, Craske MG, Mineka S, Rose RD, Waters AM, et al. Neuroticism as a common dimension in the internalizing disorders. Psychol Med. 2010;40(7):1125-36. https://doi.org/10.1017/S0033291709991449

PMid:19903363 